\title{
Zearalenone production and growth in drinking water inoculated with Fusarium graminearum
}

\author{
R. Russell • M. Paterson
}

Received: 21 July 2006 / Revised: 16 January 2007 / Accepted: 23 March 2007

(C) German Mycological Society and Springer 2007

\begin{abstract}
Production of the mycotoxin zearalenone (ZEN) was examined in drinking water inoculated with Fusarium graminearum. The strain employed was isolated from a US water distribution system. ZEN was purified with an immunoaffinity column and quantified by high-performance liquid chromatography (HPLC) with fluorescence detection. The extracellular yield of ZEN was $15.0 \mathrm{ng} \mathrm{1^{-1 }}$. Visual growth was observed. Ergosterol was also indicative of growth and an average of $6.2 \mu \mathrm{g} \mathrm{l^{-1 }}$ was obtained. Other compounds were also detected although remain unidentified. There is no equivalent information available. More work is required on metabolite expression in water as mycotoxins have consequences for human and animal health. The levels detected in this study were low. Water needs to be accepted as a potential source as it attracts high quality demands in terms of purity.
\end{abstract}

\section{Introduction}

There is increasing awareness of the significance of fungi in drinking water (Hageskal et al. 2007). This includes unsightliness, blockages, odours, pigmentation, opportunistic pathogenesis and obvious growth. However, mycotoxin production may be of the greatest concern: there are few data in this area (Paterson and Lima 2005; Gonçalves et al. 2006).

Fusarium graminearum is one of the most important mycotoxin-producing fungi. Strains produce deoxynivelenol (DON), nivalenol (NIV) and zearalenone (ZEN) (Fig. 1).

\footnotetext{
R. Russell $\cdot$ M. Paterson $(\square)$

IBB-Institute for Biotechnology and Bioengineering,

Centre for Biological Engineering, Universidade do Minho,

Campus de Gualtar,

4710-057 Braga, Portugal

e-mail: russell.paterson@deb.uminho.pt
}

ZEN is oestrogenic: it is associated with a wide range of effects on humans and animals and it may be an important aetiological agent of intoxication involving children (CAST 2003). There is high concern about oestrogens in water as evidenced by the large amount of literature and often in relation to aquatic life (e.g. Soverchia et al. 2005). NIV and DON are well-established mycotoxins (CAST 2003). Furthermore, aurofusarin (AUS) is a characteristic red pigment and toxin of the fungus which imparts this to cultures and infected grains (Malz et al. 2005).

It is not appreciated generally that growth of fungi in water is possible (Kelley et al. 2003; Criado et al. 2005): the phenomenon has been recognised for decades. Kelley et al. (2003) indicated that the fungal lipid, ergosterol (ERG), can be used to assess growth in water as in many other situations and may be useful in setting limits to the amount of fungi in water. The contribution of fungi to odours is becoming more recognised (see Gonçalves et al. 2006). Pigmentation is more difficult to associate with fungi due to the low levels of production in water. However, fungi as a whole are well known to produce pigments. There is very little information on mycotoxin production in this commodity.

Aflatoxins were detected in samples of stored tank water by Paterson et al. (1997) using immunoaffinity columns (IAC) directly to extract the compounds, in work that was in collaboration with the manufacturers. Furthermore, only trace amounts of aflatoxin $\mathrm{B}_{1}$ were detected in domestic tap water. ZEN-like compounds were observed from the only sample tested of stored tank water, which also had been analysed for aflatoxins. It is of course very important to know what the base levels of toxins are in various waters and whether further fungal growth can increase these concentrations (Paterson 2006). Criado et al. (2005) suggested that citrinin was produced in bottled water although there appeared to be inadequate controls employed in the exper- 
Fig. 1 Chemical structure of zearalenone

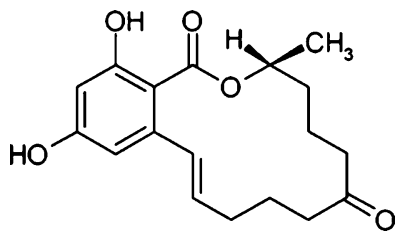

iment and the concentration was not determined. Kelley et al. (2003) provide information in a 3-year study on the significance of fungi in water distribution systems in the USA. Many secondary metabolites and mycotoxins were reported in a preliminary manner from fungi isolated during the study.

The results of inoculating a US $F$. graminearum strain in water and testing for $\mathrm{ZEN}$ are presented herein to provide a more accessible, fully described and interpreted report based on the preliminary information in Kelley et al. (2003).

\section{Materials and methods}

F. graminearum (IMI 374111) was isolated from a raw water screen of the water distribution system at Water Works Park, Detroit, MI, USA in November 1996 (Kelley et al. 2003). The fungus was identified from morphological characters by Dr. David Brayford (CABI Bioscience, UK) who was an expert in Fusarium taxonomy. Samples of water $(100 \mathrm{ml})$ were filtered through $0.45 \mu \mathrm{m}$ (Whatman) and plated onto half-strength cornmeal agar (Kelley et al. 2003) and the colonies removed for examination and preservation. The culture was isolated and grown on malt agar (Oxoid, Basingstoke, UK) at room temperature (ca. $20^{\circ} \mathrm{C}$ ). A suspension of the fungus was prepared carefully and washed twice in laboratory deionised water to contain $3 \times 10^{3}$ colonyforming units (cfu) $1^{-1}$ as determined by viable counts. The suspension was predominately conidia. The procedure was designed to give a pure aqueous spore suspension devoid of contamination with extraneous chemicals. Five Erlenmeyer flasks $(250 \mathrm{ml})$ each containing $100 \mathrm{ml}$ of drinking water (DW) from a tap located in Egham, UK were inoculated with $1 \mathrm{ml}$ (i.e. equivalent of only $3 \mathrm{cfu}$ ) of the fungal suspension and incubated on a rotary shaker at room temperature $\left(\right.$ ca. $\left.20^{\circ} \mathrm{C}\right)$ for 14 days. The small amounts of growth were estimated visually, i.e. $1=$ lowest and $3=$ highest growth.

\section{Protocol}

The basic protocol used was as follows: five flasks each containing $100 \mathrm{ml}$ of water in which $F$. graminearum had grown were filtered. The ergosterol concentration of each residue was determined (see below) to give five determinations (Fig. 2). Each 100-ml filtrate was passed through an IAC and then the column was used to analyse for ZEN (see below) which provided one pooled datum. Finally, each $100-\mathrm{ml}$ filtrate was collected separately from the IAC and analysed by gradient high-performance liquid chromatography (HPLC) for presumed secondary metabolites (see below) to provide five chromatograms, one for each filtrate.

\section{Ergosterol}

The cultures were filtered and the individual filter papers and fungus were extracted for ergosterol after 14 days when significant growth was observed. Dried filter papers containing the biomass were refluxed in $60 \mathrm{ml}$ methanol/ ethanol $(5: 1 ; \mathrm{v} / \mathrm{v})$ with $10 \%(\mathrm{w} / \mathrm{v})$ potassium hydroxide for $1 \mathrm{~h}$. Filtrates were extracted with $60 \mathrm{ml}$ petroleum ether and the extracts were rotary evaporated at $40^{\circ} \mathrm{C}$ to apparent dryness. The residue was dissolved in $2 \mathrm{ml}$ methanol and filtered through a $0.45-\mu \mathrm{m}$ filter (Millipore, Watford, UK)
Fig. 2 Ergosterol versus estimation of visual growth in the five flasks of drinking water inoculated with $F$. graminearum

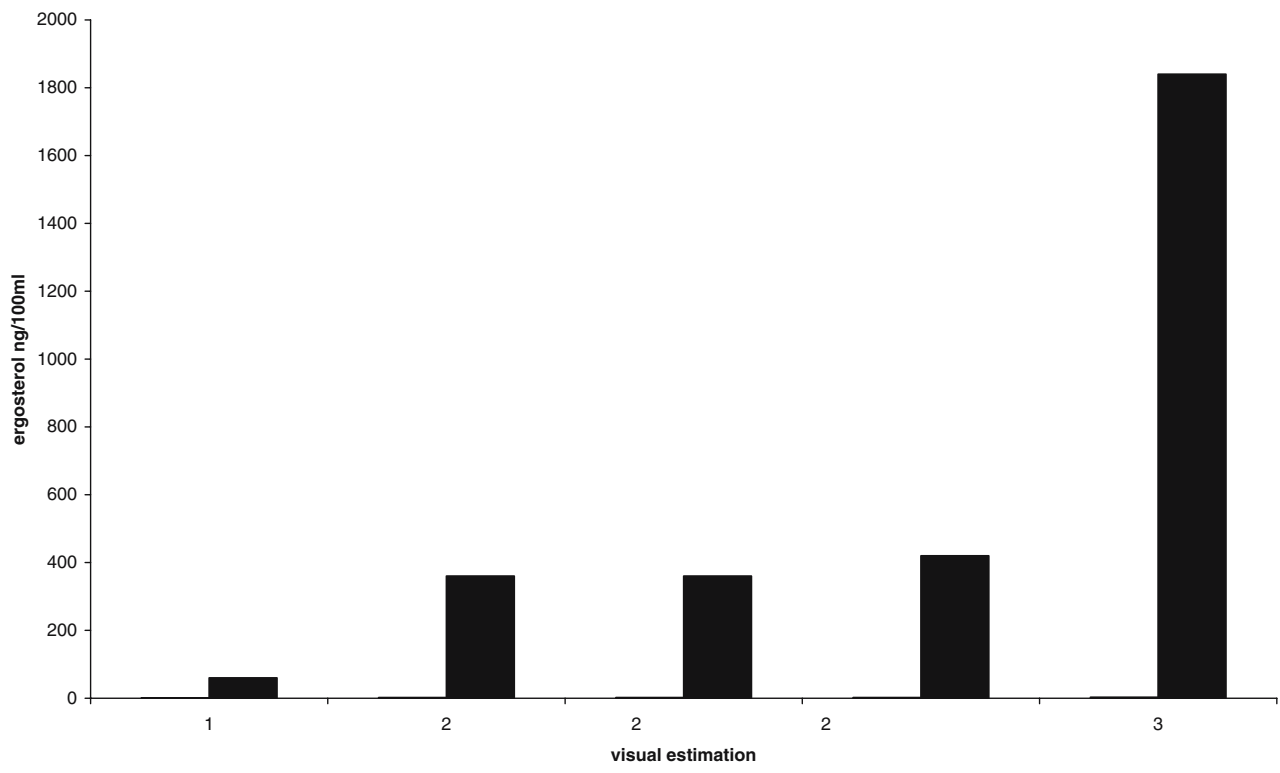




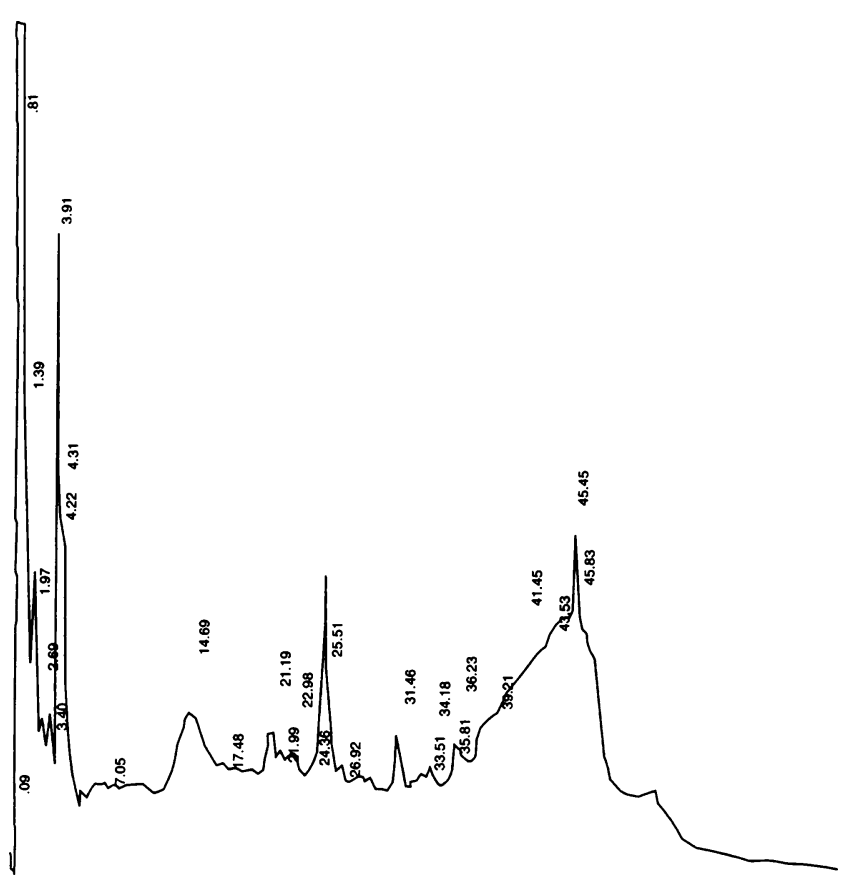

Fig. 3 HPLC chromatogram from one sample of five of unidentified extracellular metabolites of $F$. graminearum on drinking water. [HPLC conditions/equipment were Waters (a) 600; (b) 486 UV/VIS detector at $254 \mathrm{~nm}$; and (c) 746 Data Module. Column was a reversed phase Nova-Pak C18 $(3.9 \times 159 \mathrm{~mm})$. Injection volume was $100 \mu$ l. Solvent system was $\mathrm{A}=$ acetonitrile, $\mathrm{B}=$ water. Gradient was $\mathrm{A}=10 \%$, raised to $50 \%$ in $30 \mathrm{~min}, 90 \%$ in $4 \mathrm{~min}$, held for $4 \mathrm{~min}$ and lowered to $10 \%$ in $7 \mathrm{~min}$ ]

with three washes of methanol. This was rotary evaporated and re-dissolved in $200 \mu \mathrm{l} \mathrm{HPLC}$ methanol. HPLC analysis was performed using Waters equipment (600, 486 UV/VIS detector at $282 \mathrm{~nm}, 746$ data recorder). The column was a reversed phase Nova-Pak C18 $(3.9 \times 150 \mathrm{~mm})$. Elution was by HPLC grade methanol and the flow rate was $2 \mathrm{ml} \mathrm{min}^{-1}$. The retention time of ergosterol was $2.8 \mathrm{~min}$. Concentration was determined by the use of ergosterol standards (Sigma, Bracknell, UK).

\section{Zearalenone}

The filtrate of five flasks was passed through an IAC (ca.

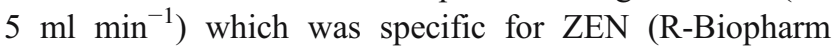
Rhone Ltd., Glasgow, UK). A control of $500 \mathrm{ml}$ DW was eluted through another column. The colour of the IAC was noted after these elutions. The columns were analysed for ZEN at R-Biopharm Rhone Ltd. (Glasgow, UK) following standard procedures as described in the company procedures document (EASI EXTRACT for zearalenone). Briefly, the column was washed by $20 \mathrm{ml}$ distilled water. Acetonitrile $(1.5 \mathrm{ml})$ was passed through the column at

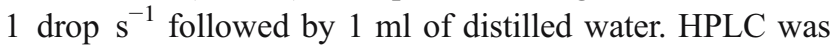
as recommended using an ODS-3 column, mobile phase was 60:40 (v:v) acetonitrile:water (pH 3.2 with acetic acid) and flow rate was $1.0 \mathrm{ml} \mathrm{min}^{-1}$. Fluorescence detection was excitation $274 \mathrm{~nm}$, emission $455 \mathrm{~nm}$. Column temperature was $40^{\circ} \mathrm{C}$. The peak area of the sample was compared with the peak area of controls of ZEN (Sigma, Bracknell, UK) to calculate concentration. ZEN had a retention time of $6.92 \mathrm{~min}$ in the standard protocol of R-Biopharm Rhone Ltd. The methods were developed with the participation of the company.

Secondary metabolites

The filtrates from the IAC were collected in $100-\mathrm{ml}$ aliquots (i.e. $5 \times$ ca. $100 \mathrm{ml}$ ) and extracted with equal volumes of chloroform after elution through the IACs. The chloroform was subjected to rotary evaporation to apparent dryness and re-dissolved in ca. $1 \mathrm{ml} \mathrm{HPLC}$ water. This was used to inject the HPLC. One sample of HPLC grade water and three of DW were extracted similarly for controls and the peaks obtained were ignored if present in the inoculated samples. The HPLC conditions are provided in Fig. 3 as adapted from Paterson and Bridge (1994). The HPLC was run at high sensitivity due to the predicted low concentration of metabolites produced in water. The tentative identities of metabolites based on retention times are not reported partly because standards were not available of all compounds. Odour detection was not attempted because of the potential health risk of inhaling volatile fungal compounds.

\section{Results}

Distinct growth was observed in all inoculated flasks whereas there was no growth in uninoculated control water as would be expected. The growth was of a "cotton wool" or gossamer morphology and was sparse compared to growth on high nutrient-containing media. However, there appeared to be a different quantity of growth in some of the flasks. One flask (Fig. 2) contained a small amount of growth [visual estimation (v.e.)=1]; another three flasks had approximately the same amount of growth $($ v.e. $=2)$ and the remaining flask had a high amount of growth (v.e. $=3$ ). The concentration of ergosterol from the flasks correlated with the estimation of growth (Fig. 2). The flasks with the v.e. of 1,2 and 3 contained approximately $0.6,4.0$ and $18.0 \mu \mathrm{g}^{-1}$ ergosterol, respectively. The average ergosterol concentration from all flasks was $6.2 \mu \mathrm{g}^{-1}$.

Furthermore, extracellular ZEN was detected from the five pooled flasks of DW $(500 \mathrm{ml})$ at $15.0 \mathrm{ng} 1^{-1}$. Intracellular ZEN was not determined. Therefore, a yield of $0.5 \mu \mathrm{g} \mathrm{ZEN} \mathrm{mg}^{-1}$ ergosterol was obtained.

Thirty-nine unidentified compounds were detected (Table 1) from the water which had been eluted through the IAC, and a typical chromatogram of these is provided 
Table 1 Detection of unidentified metabolites in drinking water which had been inoculated with $F$. graminearum

\begin{tabular}{lll}
\hline $\begin{array}{l}\text { Percentage of samples of water } \\
\text { from flasks which resulted in an }\end{array}$ & $\begin{array}{l}\text { Mean retention } \\
\text { time (min) }\end{array}$ & $\begin{array}{l}\text { Number } \\
\text { of peaks }\end{array}$ \\
HPLC peak upon analysis & & \\
\hline 100 (5 of 5$)$ & $2.0,3.4,6.8,21.2$, & 7 \\
& $25.5,34.2,36.2$ & \\
$80(4$ of 5$)$ & $22.1,23.1,27.0$, & 8 \\
& $32.8,35.9,39.5$, & \\
& $41.4,43.8$ & \\
$60(3$ of 5$)$ & $1.4,2.6,3.9,7.2$, & 7 \\
& $12.1,24.4,29.3$ & \\
$40(2$ of 5$)$ & $1.6,4.2,4.3,6.7$, & 9 \\
& $14.9,17.5,44.7$, & \\
$20(1$ of 5$)$ & $45.4,46.1$ & \\
& $1.0,3.0,6.7,13.9$, & 8 \\
Total & $15.5,26.9,28.6$, & \\
\hline
\end{tabular}

(Fig. 3; Table 1). The chromatograms gave the impression that a great deal of metabolic activity had occurred in the inoculated flasks by the observed presence of numerous peaks. A wide range of compounds were observed with different physical/chemical properties as indicated from the wide range of retention times. There were seven peaks which were present uniquely in all flasks (Table 1). These ranged in retention time from $2.0 \mathrm{~min}$ to $36.2 \mathrm{~min}$, although none were observed between 10 and $20 \mathrm{~min}$. Peaks that were common to four of five ( $80 \%$ ) flasks all eluted after $20 \mathrm{~min}$ through to $43.8 \mathrm{~min}$. Some less common peaks were observed between 10 and $20 \mathrm{~min}$ in $40 \%$ (two of five) and $20 \%$ (one of five) of samples.

One of the five chromatograms is provided in Fig. 3. The initial peaks may be discounted as the compounds probably did not interact with the column. Particularly large peaks were observed at $3.91,14.69,25.51$ and apparently $45.45 \mathrm{~min}$. However, the increase in absorbance from 33.51 to $43.53 \mathrm{~min}$ is due to the change in solvents from the gradient used. The subsequent decrease in absorbance from $45.83 \mathrm{~min}$ is correspondingly from the rapid change in solvents employed as described in the legend to Fig. 3.

Many fewer peaks were observed from control DW and especially HPLC water controls. A red pigment was observed on the packing material of the IAC after the spent DW had been eluted.

\section{Discussion}

ZEN was detected readily in water inoculated with $F$. graminearum. The control of uninoculated water did not contain detectable ZEN. The fact that (a) the known ZEN producer, $F$. graminearum, was used in the experiment, (b) a specific IAC was employed to isolate and purify ZEN and (c) an HPLC peak was observed at the appropriate retention time are good proofs that ZEN was the compound detected. In contrast, Criado et al. (2005) employed qualitative thinlayer chromatography (TLC) for citrinin with conventional solvent purification. In the present case, ZEN was only analysed in the water and not the biomass. Hence, any very small amounts of ZEN added in the biomass as inoculum can be discounted. In addition, the inoculum was carefully prepared and washed as described and levels would have been extremely low, if present at all, and certainly below the concentration detected after 14 days growth.

Furthermore, the amount of ergosterol added in the inoculum would have been very small. It can been estimated that a single conidium contains 5 pg ergosterol (Pasanen et al. 1999). Each flask was inoculated with only $3 \mathrm{cfu}$. Finally, the visual estimation of biomass in the inoculum used here was zero indicating low or no ERG.

ZEN is now regulated in many countries (Table 2). It is structurally related to zearalenol, an anabolic growth promoter banned in the European Union in 1988. Statutory limits of ZEN in cereals vary from 50 to $1,000 \mu \mathrm{g} \mathrm{kg}^{-1}$ (FAO 2004), and the levels detected in the water in this report are low and may not represent a particular threat. However, ZEN mimics the effects of the female hormone oestrogen and induces feminization at dietary concentrations of "less than" $1 \mathrm{mg} \mathrm{kg}^{-1}$ feed (CAST 2003). The levels produced in water in this report were approximately $10^{5}$ lower than that value and would not appear to be a risk per se. On the one hand, water is likely to be consumed at a high concentration compared to feed, and water fed to animals is likely to be impure and may be capable of supporting higher levels of ZEN production. One scenario which may be worth considering is if contaminated water was used to produce feed (especially if evaporation was involved) and also as a direct source of drinking water. In this case there may be sufficient ZEN to pass a threshold value for activity to occur. These points are balanced by the fact that many other factors would tend to reduce concentrations of ZEN in vivo compared to the experimental

Table 2 Countries with regulations concerning zearalenone in food and feeds (FAO 2004)

\begin{tabular}{lll}
\hline Armenia & Hungary & Mozambique \\
Austria & Indonesia & Romania \\
Belarus & Iran & The Russian Federation \\
Brazil & Israel & Serbia and Montenegro \\
Canada & Italy & Singapore \\
Chile & Japan & Slovenia \\
Colombia & Latvia & Ukraine \\
Cyprus & Lithuania & Uruguay \\
Estonia & Republic of Moldova & \\
France & Morocco & \\
\hline
\end{tabular}


procedures employed in this report (e.g. competition from other microorganisms). However, the increased effects of combinations of mycotoxins and the inherently high purity standards demanded of drinking water need to be considered.

More work is required to provide reliable identifications of the other metabolites produced in water (Fig. 3). However, the data provided are at least a first step to indicate that secondary metabolites are produced. Of course, the peaks may represent other compounds such as amino acids, or degradation products of metabolism in general. The detection of the red pigment is interesting and it was possibly AUR, although more work is required to confirm identity. AUR is the well-known and characteristic pigment from this fungus (Malz et al. 2005).

A key issue in this work relates to detection limits, repeatability and accuracy of ZEN analysis. It is intended that this work will provide a platform for further work using the most sensitive equipment such as mass spectrometry and magnetic resonance imaging analyses. In this present study, ZEN was produced in amounts which were quantified readily. However, the report of citrinin in bottled water production in (Criado et al. 2005) is undermined by the lack of data from controls. The current report indicated that the production of ZEN from $F$. graminearum in water is possible and provides information which may be useful in establishing base lines especially to indicate if abnormal concentrations are recorded at any time (Paterson 2006). The data represent the first genuine report of mycotoxin production in drinking water and water in general. In conclusion, ZEN was produced readily in water from a strain of $F$. graminearum isolated from a water distribution system. In addition, the methods are recommended to monitor mycotoxin levels in water intended for human consumption and may form the basis of a standard method.

Acknowledgement The author received the grant SFRH/BPD/ 14923/2004 from Fundação para a Ciência e a Tecnologia, Portugal.

\section{References}

CAST (2003) Mycotoxins: risks in plant, animal, and human systems. Council for Agricultural Science and Technology, Ames, IA.

Criado MV, Fernández PVE, Badessari A, Cabral D (2005) Conditions that regulate the growth of moulds inoculated into bottled mineral water. Int J Food Microbiol 99:343-349

FAO (2004) Worldwide regulations for mycotoxins in food and feed in 2003. FAO food and nutrition paper 81. Food and Agriculture Organisation of the United Nations, Rome

Gonçalves AB, Paterson RRM, Lima N (2006) Survey and significance of filamentous fungi from tap water. Int J Hyg Environ Health 209:257-264

Hageskal G, Gausted P, Heier BT, Skaar I (2007) Occurrence of moulds in drinking water. Journal of Applied Microbiology (OnlineEarly Article). DOI 10.1111/j.1365-2672.2006.03119x

Kelley J, Kinsey G, Paterson R, Brayford D, Pitchers R, Rossmore H (2003) Identification and control of fungi in distribution systems. Awwa Research Foundation and American Water Works Association, Denver

Malz S, Grell MN, Thrane C, Maier FJ, Rosager P, Felk A, Albertsen KS, Salomon S, Bohn L, Schäfer W, Giese H (2005) Identification of a gene cluster responsible for the biosynthesis of aurofusarin in the Fusarium graminearum species complex. Fungal Genet Biol 42:420-443

Pasanen A-L, Pietila KY, Pasanen P, Kalliokoski P, Tarhanen J (1999) Ergosterol content in various fungal species and biocontaminated building materials. Appl Environ Microbiol 65:138-142

Paterson RRM (2006) Fungi and fungal toxins as weapons. Mycol Res 110:1003-1010

Paterson RRM, Bridge PD (1994) Biochemical techniques in filamentous fungi. IMI Technical Series CAB International, Wallingford

Paterson RRM, Lima N (2005) Fungal contamination of drinking water. In: Lehr J, Keeley J, Lehr J, Kingery III TB (eds) Water encyclopedia. Wiley, New York. DOI 101002/047147844X.wq1516

Paterson RRM, Kelley J, Gallagher M (1997) Natural occurrence of aflatoxins and Aspergillus flavus (LINK) in water. Lett Appl Microbiol 25:435-436

Soverchia L, Ruggeri B, Palermo F, Mosconi G, Cardinaletti G, Scortichini G, Gatti G, Polzonetti-Magni AM (2005) Modulation of vitellogenin synthesis through estrogen receptor beta-1 in goldfish (Carassius auratus) juveniles exposed to $17-\beta$-estradiol and nonylphenol. Toxicol Appl Pharmacol 209:236-243 